Purwaningrum, Y. · Y. Asbur · D. Kusbiantoro · Khairunisyah

\title{
Respons fisiologi dan hasil lateks tanaman karet klon GT 1 di kebun karet rakyat terhadap sistem eksploitasi dan curah hujan
}

Sari Klon GT 1 adalah klon Slow Starter (SS) dimana perubahan sukrosa menjadi partikel karet di dalam pembuluh lateks berlangsung lambat dan pada saat gugur daun hasil lateks lebih stabil. Penelitian ini bertujuan untuk mengetahui hubungan curah hujan dan sistem eksploitasi terhadap fisiologi dan hasil lateks klon GT1. Penelitian dilaksanakan di Kabupaten Langkat Kecamatan Besitang Sumatera Utara, ketinggian tempat 500 - $700 \mathrm{~m}$ di atas permukaan laut. Analisa fisiologi lateks di PT. Sucofindo Indonesia. Tanaman yang digunakan adalah klon GT 1 umur 25 tahun dengan besar lilit batang antara $60-75 \mathrm{~cm}$, diukur dengan ketinggian $130 \mathrm{~cm}$ dari permukaan tanah. Metode percobaan menggunakan Rancangan Acak Kelompok. Perlakuan terdiri dari kombinasi panjang alur sadap dan aplikasi stimulan. Panjang alur sadap, terdiri dari panjang alur sadap $1 / 4$ spiral, 1/2 spiral, dan 1/8 spiral, sementara aplikasi stimulan terdiri dari stimulan cair dan stimulan gas. Semua perlakuan diulang tiga kali. Hasil penelitian menunjukkan bahwa panjang alur sadap pendek dan aplikasi stimulan cair memiliki kadar sukrosa lateks tinggi . Aplikasi stimulan gas menunjukkan kadar sukrosa lateks yang tinggi pada panjang alur sadap panjang. Kadar tiol belum menunjukkan tingkat stress pada klon GT 1 dapat terlihat dari kadar tiolnya berkisar 0,84 - 1,10 mM. Produksi lateks klon GT 1 lebih dipengaruhi oleh sistem ekploitasi daripada curah hujan.

Kata kunci: Fisiologi lateks · Hevea brasiliensis · klon GT 1 - slow starter

\section{Physiological response and latex yield of GT 1 clone rubber plant in smallholder rubber plantation on exploitation system and rainfall}

\begin{abstract}
GT 1 is a Slow Starter (SS) clone where the change of sucrose into rubber particles in the latex vessels is slow, and at the time of leaves fall, the latex yield is more stable. This study aimed to determine the relationship between agro-climate and exploitation system on the physiology and yield of latex clone GT1. The research was carried out in Langkat, Besitang, North Sumatra, at an altitude of $500-700 \mathrm{~m}$ above sea level. Physiological traits analysis of latex was conducted at PT. Sucofindo Indonesia. The plant used was a 25 years old GT 1 clone with a trunk circumference of $60-75 \mathrm{~cm}$, measured at the height of $130 \mathrm{~cm}$ from the ground. The experimental design used Randomized Block Design. The treatments consisted by combination of tapping groove length levels and stimulant application. Tapping groove length consisted of $1 / 4,1 / 2$, and $1 / 8$ spiral, while stimulant application consisted of liquid and gas stimulant. The results showed that short tapping groove length and liquid stimulant application had high latex sucrose content, as given by long tapping groove length and gas stimulant application. Thiol level did not show the stress level in the GT 1 clone, it could be seen from the thiol level of $0.84-1.10 \mathrm{mM}$. Latex production of GT 1 clones was more influenced by the exploitation system than by rainfall.
\end{abstract}

Keywords: GT 1 clone $\cdot$ Hevea brasiliensis $\cdot$ Latex phyisiology $\cdot$ Low starter

Diterima : 10 Maret 2021, Disetujui : 13 Juni 2021, Dipublikasikan : 1 Agustus 2021

DOI: https:// doi.org/10.24198/ kultivasi.v20i2.33622

Purwaningrum, Y. 1 Y. Asbur ${ }^{1} \cdot$ D. Kusbiantoro ${ }^{2} \cdot$ Khairunisyah $^{2}$

${ }^{1}$ Program Studi Agroteknologi, Fakultas Pertanian, Universitas Islam Sumatera Utara, Medan

2Program Agribisnis, Fakultas Pertanian, Universitas Islam Sumatera Utara, Medan

Korespondensi: yayuk.purwaningrum@fp.uisu.ac.id 


\section{Pendahuluan}

Perkebunan karet di Indonesia sebagian besar adalah perkebunan rakyat yaitu $85,06 \%$, perkebunan besar milik swasta $7,9 \%$ dan perkebunan milik negara sebesar 6,95\% (Ditjenbun, 2012). Beberapa jenis klon yang banyak digunakan di perkebunan rakyat di Indonesia umunya adalah klon GT 1. Klon GT-1 merupakan klon slow starter (SS), yaitu klon-klon metabolisme rendah sampai sedang yang memiliki ciri spesifik di antaranya responsif terhadap pemberian stimulan, relatif lebih tahan terhadap tekanan eksploitasi, dan kulit pulihan umumnya tebal sehingga potensial untuk dimanfaatkan (Syukur, 2019).

Kabupaten Langkat memiliki ketinggian 500-700 $\mathrm{m}$ di atas permukaan laut (dpl), dengan kondisi lahan berbukit, ordo tanah Ultisol, jumlah curah hujan $147,94 \mathrm{~mm} /$ bulan, hari hujan 12,33 hari/bulan, rata-rata jumlah bulan basah, lembab, dan kering berturut turut 1, 8, dan 3 bulan (Google Earth, 2019; Gunarsih dan Kartasapoetra, 2012).

Perkebunan karet di Indonesia hampir setiap tahun menghadapi musim kemarau, yang di beberapa daerah berlangsung cukup panjang selama dua sampai tiga bulan (bulan Januari sampai Maret) (Sayurandi et al., 2017). Periode kering lebih dari dua bulan akan menyebabkan terjadinya gangguan pertumbuhan dan kehilangan produksi yang cukup besar. Pengalaman menunjukkan bahwa kemarau panjang berdampak kepada penurunan produktivitas tanaman yang berakibat kerugian pada usaha perkebunan (Kramer, 1983; Wijaya dan Boerhendhy, 1988).

Untuk mengantisipasi ketidakcukupan air pada proses transpirasi, setiap klon karet secara fisiologi memiliki respon yang berbeda terhadap waktu dan lama menggugurkan daunnya. Gugur daun tersebut dapat terjadi secara serentak maupun secara bertahap (Priyadarshan, 2001; Siregar et al., 2007; Gireesh et al., 2011). Sejumlah hasil penelitian Oktavia dan Lasminingsih (2010), Ardika et al. (2011), Junaidi et al. (2015), dan Sayurandi et al. (2017) menyatakan bahwa kekeringan berakibat turunnya hasil lateks yang paling tinggi terdapat pada saat tanaman dalam kondisi gugur daun total dan pembentukan daun muda.

Setiap klon memiliki sifat karakteristik yang spesifik, dalam mempertimbangkan sistem eksploitasi kita harus melihat lokasi perkebunan (iklim) dan karakter fisiologi setiap klon (Siregar, 2014). Beberapa sifat spesifik klon SS selain memiliki sifat relatif lebih tahan terhadap tekanan eksploitasi, seperti sangat respons terhadap stimulan dan umumnya memiliki kulit pulihan yang tebal sehingga potensial untuk dimanfaatkan, juga mempunyai kemampuan relatif lebih stabil pada umur 12 sampai 17 tahun, kemudian meningkat secara perlahan hingga mencapai puncak produksi sampai menjelang peremajaan, namun pada saat awal sadap menghasilkan produksi yang rendah (Sumarmadji et al., 2005 dan 2006, Siregar et al., 2001 dan 2007).

Rangkaian sistem sadap yang digunakan sepanjang waktu produksi (TM) pada tanaman karet umur (20 - 25 tahun) disebut sistem eksploitasi (Sumarmadji dan Atminingsih, 2013). Dalam mengurangi efek negatif minimum terhadap tanaman dan meningkatkan produksi karet, penelitian eksploitasi terus dilakukan untuk mencari sistem yang paling tepat sesuai dengan karakter fisiologi klon karet dan iklim. Tiap klon karet mempunyai respons yang berbeda-beda terhadap sistem eksploitasi dan perubahan pola curah hujan (Sumarmadji, 2011). Beberapa klon SS seperti GT 1, RRIM 600, PR 261, PB 235, PB 200, dan RRIM 703 menggunakan sistem eksploitasi pada awal sadap berupa panjang irisan setengah lilit batang dan frekuensi sadap tiga hari sekali (S2 d/3), selanjutnya pada umur 10 tahun adalah S2 d/2 (Sumarmadji, 2008).

Stimulan mengandung formula yang dibuat dengan berbagai vitamin dan zat pengatur tumbuh. Peranannya mencegah penyumbatan pembuluh lateks sehingga lateks menetes lebih lama sehingga meningkatkan produksi lateks. Pemberian stimulan berpengaruh terhadap fisiologis tanaman karet, antara lain: (1) membuat dinding sel elastis, (2) mempercepat dan meningkatkan aktivitas enzim dalam biosintetis lateks, dan (3) membuat daerah aliran lateks menjadi semakin cepat. Ketiga peran stimulan tersebut berpengaruh terhadap peningkatan kecepatan aliran lateks sehingga lateks yang dihasilkan lebih banyak (Eschbach and Lacrotte, 1989).

Penggunaan stimulan tidak menambah jumlah getah (lateks) yang ada di pohon, melainkan hanya menunda penyumbatan sehingga lateks menetes lebih lama dan hasil yang ditampung dapat lebih banyak. 
Penyadapan pun dapat lebih efisien karena irisan sadap umumnya lebih pendek (cukup 10 $\mathrm{cm}$ sampai seperempat lingkaran dari normalnya setengah lingkaran atau lebih) sehingga dengan irisan lebih pendek maka konsumsi kulit tanaman juga lebih hemat dan umur tanaman diharapkan lebih panjang (Eschbach and Lacrotte, 1989).

Tiap klon pada dasarnya memiliki respons yang berbeda terhadap pola musim. Di Indonesia, penelitian tentang hal tersebut masih sangat terbatas. Pengujian-pengujian klon pada umumnya belum mempertimbangkan respons tiap klon secara spesifik terhadap perubahan musim, meskipun klon-klon unggul sudah ditanam pada berbagai lokasi kebun. Berdasarkan hal tersebut, perlu penelitian untuk mengetahui hubungan curah hujan dan sistem eksploitasi terhadap fisiologi dan hasil lateks klon GT1, dan mengetahui sistem eksploitasi yang tepat sesuai klon dan lokasi.

\section{Bahan dan Metode}

Penelitian dilaksanakan di Desa Halaban Dusun Sidorejo, Kabupaten Langkat Kecamatan Besitang, Sumatera Utara, dengan ketinggian tempat 500 - $700 \mathrm{~m} \mathrm{dpl}$, dan ordo tanah ultisol. Area koordinat penelitian $3^{\circ} 55^{\prime} 35,36^{\prime \prime}$ LU, dan 9758'27,68' BT. Data curah hujan diambil dari Badan Meteorologi Klimatologi dan Geofisika (BMKG) Sampali, Medan. Tanaman yang digunakan adalah klon GT 1 umur 25 tahun, jarak tanam $3 \mathrm{~m} \times 2,5 \mathrm{~m}$, dan lilit batang $60-75$ cm diukur pada ketinggian $130 \mathrm{~cm}$ dari permukaan tanah.

Metode penelitian menggunakan Rancangan Acak Kelompok dengan tiga ulangan. Perlakuannya adalah kombinasi antara panjang alur sadap dengan aplikasi stimulan. Panjang alur sadap terdiri dari $1 / 4$ spiral disadap 3 hari sekali (S4d3), panjang alur sadap $1 / 2$ spiral disadap 3 hari sekali (S2d3), dan panjang alur sadap 1/8 spiral disadap 3 hari sekali (S8d3). Aplikasi stimulan terdiri dari stimulan cair dengan konsentrasi 2,5\% diberikan 15 hari (ET/15d) dan stimulan gas kosentrasi 90\% diberikan 27 hari sekali (ETG/27d).

Tanaman yang digunakan dalam penelitian ini sebanyak 150 tanaman. Tanaman sampel untuk setiap perlakuan diambil sebanyak 5 tanaman yang dipilih secara acak. Pengamatan dilakukan terhadap variabel hasil, fisiologi lateks (kadar sukrosa, fosfat anorganik (Pi), dan thiol), serta curah hujan sebagai pengamatan penunjang.

Data dianalisis menggunakan Statistical Analysis System (SAS) Software 9.1 (SAS Institute, Cary, North Carolina, USA). Apabila perlakuan yang diuji berbeda nyata dilanjutkan dengan Duncan's Multiple Range Tests a $=0.05$.

\section{Hasil dan Pembahasan}

Rataan fisiologi lateks klon GT 1 tertera pada Tabel 1. Hasil analisis statistik diketahui bahwa perlakuan sistem eksploitasi mempengaruhi fisiologi lateks, yaitu kadar sukrosa dan Pi, kecuali thiol tidak berbeda nyata. Sistem ekploitasi S4d3 ET/15d memiliki kadar sukrosa lateks lebih tinggi pada klon GT 1 dibandingkan dengan perlakuan lainnya, tetapi tidak berbeda nyata dengan perlakuan S8d3 ET/15d. Data ini menunjukkan bahwa kadar sukrosa lateks tinggi pada klon GT 1 bila diberi stimulan cair (ET/15d) dengan panjang alur sadap yang pendek (S4 dan S8), sedangkan kadar sukrosa tinggi bila panjang alur sadap panjang (S2) untuk aplikasi stimulan gas (ETG/27d). Hal ini disebabkan klon GT 1 merupakan klon SS dimana klon ini respons terhadap stimulan, dengan penyadapan yang pendek, sehingga energinya (Pi) lebih besar dan didukung oleh frekuensi stimulan sebulan dua kali sehingga tanaman meningkatkan laju kapasitas pembentukan gula (sukrosa). Hasil penelitian ini ditemukan juga oleh Karyudi, et al. (2006), Herlinawati dan Kuswanhadi (2012), Junaidi (2013), serta Purwaningrum (2016) yang menyatakan dengan penggunaan panjang irisan sadap yang pendek dan aplikasi stimulan mampu meningkatkan produktivitas tanaman karet.

Fosfat anorganik merupakan senyawa dasar $\mathrm{P}$ yang berikatan dengan ADP menghasilkan ATP, energi tersebut digunakan untuk merubah sukrosa menjadi lateks. Hasil analisis statistik pada Tabel 1 menunjukkan sistem eksploitasi mempengaruhi kadar Pi lateks klon GT 1. Secara umum klon SS (klon GT 1) memiliki rataan nilai Pi lateks tinggi. Hal ini sejalan dengan karakteristik klon SS dimana klon ini mengandung fosfat anorganik tinggi (Gohet et al., 2008; Herlinawati dan Kuswanhadi, 2018). Kadar fosfat anorganik lateks klon GT 1 tinggi pada sistem ekploitasi 
S4d3 dengan ETG/27d dibandingkan yang lainnya. Fosfat anorganik merupakan indikator bagi aktivitas metabolik tanaman yang berperan untuk mengubah bahan baku (sukrosa) menjadi partikel karet (Jacob et al., 1998). Rendahnya frekuensi aplikasi stimulan, yaitu $27 \mathrm{~d}$, menyebabkan tanaman tidak terlalu intensif dieksploitasi, sehingga tanaman mempunyai cukup waktu untuk membentuk energi tinggi (ATP). Ketersediaan energi yang cukup akan memperlancar proses perubahan hasil fotosintesis menjadi sukrosa (Junaidi, 2013).

Senyawa yang dihasilkan tanaman karet yang berfungsi sebagai antioksidan untuk melindungi dari tekanan eksploitasi adalah tiol. Tiol sebagai antioksidan yang berfungsi melindungi dari stres oksidatif sebagai akibat aktifnya metabolisme dalam sel. Tiol juga menunjukkan status respons tanaman terhadap tekanan eksploitasi (Sumarmadji et al., 2005). Intensitas eksploitasi berbanding terbalik dengan kadar tiol, dimana semakin tinggi intensitas eksploitasi, kadar tiolnya rendah (Jacob et al., 1998).

Sistem eksploitasi tidak berbeda nyata terhadap kadar thiol, dengan kata lain perlakuan tidak mempengaruhi kadar tiol lateks pada klon GT1, sehingga kadar tiol belum menunjukkan tingkat stress pada klon GT 1 . Hal ini dapat terlihat dari kadar tiolnya berkisar antara $0,84-1,10 \mathrm{mM}$. Kadar tiol pada klon SS pada umur 20 tahun ke atas biasanya tinggi (Sumarmadji, 2006). Menurut Jacob et al. (1998), kadar tiol optimal 0,4 - 0,9 mM. Hasil ini mengindikasikan walaupun terjadi perbedaan kadar tiol dengan perlakuan sistem eksplotasi, akan tetapi masih dalam tahap wajar, karena nilai stres yang rendah.

Hasil analisis statistik secara umum menunjukkan sistem eksplotasi mempengaruhi hasil lateks pada klon GT 1 (Tabel 2). Sistem eksplotasi S2d3 ETG/27d memberikan hasil lateks tertinggi pada bulan Januari, Februari, Maret, dan Mei. Perlakuan S8d3 ETG/27d menghasilkan lateks tertinggi di bulan April, Juni, dan Juli. Intensitas aplikasi stimulan gas frekuensi rendah (ETG/27d), sudah mampu untuk meningkatkan produksi lateks pada klon GT 1. Aplikasi stimulan gas yang tidak terlalu intensif (27d) pada tanaman sudah cukup untuk membentuk bahan sukrosa menjadi lateks (Jacob et al., 1998).

Tabel 1. Fisiologi Lateks klon GT 1 dengan perlakuan sistem eksploitasi.

\begin{tabular}{cccc}
\hline \multirow{2}{*}{ Perlakuan } & \multicolumn{3}{c}{ Kandungan Lateks } \\
\cline { 2 - 4 } & sukrosa & Pi & thiol \\
\cline { 2 - 4 } & & $\ldots \ldots \ldots \mathrm{mM} \ldots \ldots .$. & $0.93 \mathrm{a}$ \\
S2d3 ET/15d & $4.26 \mathrm{c}$ & $25.48 \mathrm{~b}$ & $1.10 \mathrm{a}$ \\
S4d3 ET/15d & $10.50 \mathrm{a}$ & $25.90 \mathrm{~b}$ & $1.04 \mathrm{a}$ \\
S8d3 ET/15d & $10.06 \mathrm{ab}$ & $21.46 \mathrm{c}$ & $0.91 \mathrm{a}$ \\
S2d3 ETG/27d & $9.22 \mathrm{~b}$ & $24.62 \mathrm{~b}$ & $0.90 \mathrm{a}$ \\
S4d3 ETG/27d & $2.48 \mathrm{~d}$ & $30.16 \mathrm{a}$ & $0.84 \mathrm{a}$ \\
S8d3 ETG/27d & $3.16 \mathrm{~d}$ & $25.48 \mathrm{~b}$ & \\
\hline
\end{tabular}

Keterangan: Angka dalam kolom yang diikuti oleh notasi yang berbeda menunjukkan berbeda nyata berdasarkan uji Duncan $(\mathrm{P}=0.05)$.

Tabel 2. Hasil Lateks klon GT 1 dengan perlakuan sistem eksploitasi.

\begin{tabular}{|c|c|c|c|c|c|c|c|}
\hline \multirow[t]{2}{*}{ Perlakuan } & \multicolumn{7}{|c|}{ Hasil Lateks (kg/ha) } \\
\hline & Januari & Februari & Maret & April & Mei & Juni & Juli \\
\hline S2d3 ET/15d & $616.00 \mathrm{~b}$ & $693.44 \quad b$ & $204.66 \mathrm{~cd}$ & $97.99 \mathrm{~d}$ & $173.66 \mathrm{~d}$ & $273.45 \mathrm{c}$ & $322.78 \mathrm{e}$ \\
\hline S4d3 ET/15d & $792.00 \mathrm{a}$ & $430.58 \mathrm{c}$ & $233.41 \mathrm{bc}$ & $148.46 \mathrm{bc}$ & 207.58 c & 307.71 с & $347.00 \mathrm{c}$ \\
\hline S8d3 ET/15d & $628.32 \mathrm{~b}$ & 397.01 & $194.45 \mathrm{~d}$ & $168.31 \mathrm{~b}$ & $254.03 \mathrm{~b}$ & $375.70 \mathrm{~b}$ & 347.74 bc \\
\hline S2d3 ETG/27d & 833.36 a & 3148.49 a & $346.33 \mathrm{a}$ & $149.83 \mathrm{bc}$ & $299.20 \mathrm{a}$ & $398.23 \mathrm{~b}$ & $350.04 \mathrm{~b}$ \\
\hline S4d3 ETG/27d & $598.40 \mathrm{~b}$ & $250.48 \mathrm{~d}$ & $250.48 \mathrm{~b}$ & $138.63 \mathrm{c}$ & 226.16 c & $322.03 \mathrm{c}$ & $333.34 \mathrm{~d}$ \\
\hline S8d3 ETG/27d & $627.44 \mathrm{~b}$ & $201.03 \mathrm{~d}$ & $201.03 \mathrm{~cd}$ & $222.36 \mathrm{a}$ & $267.52 \mathrm{~b}$ & $465.61 \mathrm{a}$ & $551.68 \mathrm{a}$ \\
\hline
\end{tabular}

Keterangan: Angka dalam kolom yang sama yang diikuti oleh notasi yang berbeda menunjukkan berbeda nyata berdasarkan uji Duncan $(\mathrm{P}=0.05)$. 


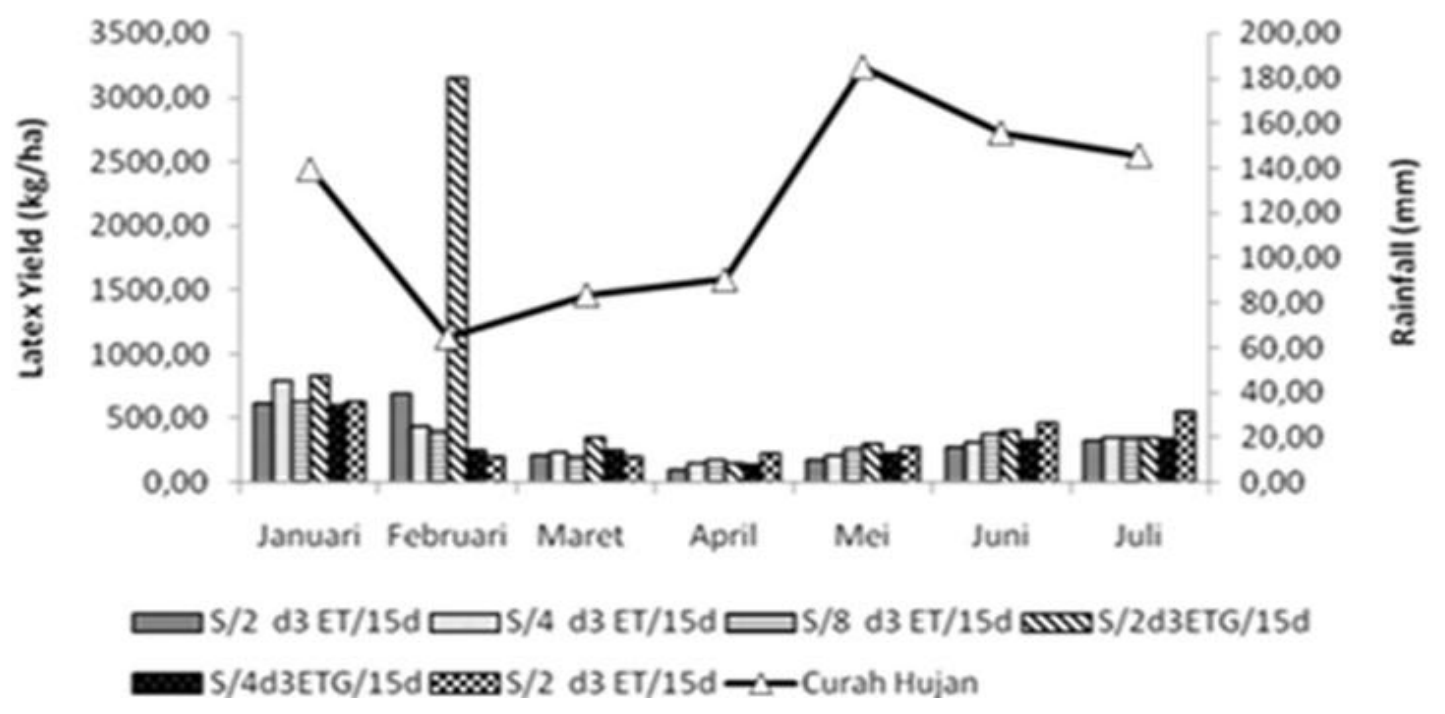

Gambar 1. Pengaruh fluktuasi curah hujan (mm) dengan hasil lateks (kgha-1) klon GT 1 dengan berbagai sistem eksploitasi

Hasil pada Gambar 1 memperlihatkan hasil lateks tertinggi pada klon GT 1 dibulan Februari dan terendah di bulan April. Kondisi tanaman di bulan Februari dalam keadaan gugur daun dan lingkungan ekstrim kering, namun klon GT 1 mampu untuk menghasilkan lateks tinggi. Hal ini menunjukkan bahwa hasil lateks klon GT 1 hanya sedikit dipengaruhi oleh kadar air yang ada di dalam tanah atau kondisi lingkungan. Karakter klon GT 1 yang tergolong SS, dimana kemampuan mengubah bahan baku sukrosa menjadi lateks relatif lebih lambat, sehingga pada musim kemarau (Januari-Maret) masih memiliki cadangan sukrosa yang tinggi yang dapat diubah menjadi lateks (Purwaningrum, 2016).

Kondisi daun di bulan April dalam kondisi pembentukan daun sehingga hasil lateks rendah, dimana secara umum hasil fotosintesis pada tanaman dari daun di alokasikan untuk pertumbuhan, hasil lateks, dan cadangan nutrisi di dalam sel. Pola pembagian asimilat ke masing-masing bagian berbeda pada setiap tanaman, tergantung pada jenis klon, umur dan kondisi lingkungan tumbuh. Beberapa tanaman terdapat pembagian yang berimbang antara pertumbuhan dan hasil, akan tetapi ada juga yang tidak berimbang pembagiannya. Berdasarkan hasil penelitian ini diketahui bahwa klon GT 1 memiliki pembagian asimilat lebih ke arah hasil pembentukan daun dibandingkan dengan ke arah lateks. Hal ini sejalan dengan sejumlah hasil penelitian, seperti Ardika (2011), Siregar (2014), Purwaningrum
(2016), dan Sayurandi et al. (2017) yang menyatakan bahwa penurunan hasil lateks pada saat pembentukan daun muda disebabkan hasil pembagian asimilat lebih ke arah hasil pembentukan daun dibandingkan pada lateks.

\section{Kesimpulan}

Berdasarkan uraian di atas, hasil penelitian menunjukkan bahwa :

1. Kadar sukrosa lateks tinggi dengan sistem eksploitasi aplikasi stimulan cair dan panjang alur sadap pendek (S4d3 ET/15d dan S8d3 ET/15d), sementara pada stimulan gas diperoleh dengan panjang alur sadap panjang (S2d3 ETG/27d). Klon GT 1 memiliki kadar Pi tinggi. Kadar tiol belum menunjukkan tingkat stress pada klon GT 1.

2. Hasil lateks klon GT 1 tidak dipengaruhi oleh curah hujan.

3. Sistem ekploitasi yang sesuai untuk klon GT 1 di lokasi Langkat adalah S4d3 ET/15d dan S2d3 ETG/27d

\section{Ucapan Terima Kasih}

Penghargaan dan ucapan terima kasih disampaikan kepada Kementerian Riset, Teknologi, dan Pendidikan Tinggi, Direktorat Jenderal Penguatan Riset dan Pengembangan, Direktorat Riset dan Pengabdian Masyarakat 
yang mendanai pelaksanaan penelitian ini melalui Penelitian Kompetitif Nasional tahun 2018 sampai 2020 dan LLDIKTI Wilayah I, Terima kasih kepada pekebun karet rakyat di Langkat dan PT Sucofindo yang telah memberikan izin lahan dan laboratorium.

\section{Daftar Pustaka}

Ardika, R., A. N. Cahyo, dan T. Wijaya. 2011. Dinamika gugur daun dan produksi berbagai klon karet kaitannya denga kandungan air tanah. J. Penelitian Karet, 29(2): 102-109.

Ditjebun. 2012. Luas Areal Karet dan Produktivitas Perkebunan di Indonesian, 2008-2012. Rubber Area by Province in Indonesia, 2008-2012. Directorate General of Estate.

Eschbach, J.M. and R. Lacrote. 1989. Factor influencing response to hormonal yield stimulation: limits of this stimulation. Plant Physiology of Rubber Tree Latex. Boca Raton, CRC Press, Plantations 5(3): 327-329.

Gireesh, T., S. Raj, K. K. Midin, and V. C. Mercykutty. 2011. Rubber yield of certain clones of Hevea brasiliensis and relationship with climate variables. J.Natural Rubber Research, 24(1): 54-60.

Google earth.

2019.

https://earth.google.com/web/@0,$49.7426,0 \mathrm{a}, 22251752.77375655 \mathrm{~d}, 35 \mathrm{y}, 0 \mathrm{~h}, 0 \mathrm{t}, 0 \mathrm{r}$ $\angle$ data $=$ KAE (diakses 20 Mei 2020).

Gohet, E, C. Scomparin, E. Cavaloc et al. 2008. Influence of ethepon stimulation on latex physiological parameter and conquences on latex diagnosis implementary in Rubber Agro-Industry. IRRDB Workshop. Latex Harvesting Technology.

Gunarsih, A. dan Kartasapoetra. 2012. Klimatologi: Pengaruh Iklim terhadap Tanah dan Tanaman Edisi Revisi. Bumi Aksara. Jakarta.

Herlinawati, A. dan Kuswanhadi. 2012. Pengaruh Penggunaan Stimulan Gas terhadap Produksi dan Karakter Fisiologi Klon Karet BPM 24. J. Penelitian Karet, 2012, 30(2) : 100-107.

Herlinawati, A. dan Kuswanhadi. 2018. Effect of ethephon stimulation on yield and latex physiology on various irr clones. J. Nat. Rubb. Res. 2017, 35 (2) : 149 - 158 Indonesian.

Jacob, J. L., J. C. Prevot, R. Lacrotte, A. Clement, E. Serres, and E. Gohet. 1998. Clonal Typology of Laticifer Functioning in Hevea brasiliensis. Plant Physiology of Rubber Tree Latex. Boca Raton, CRC Press, Plantations 2(5): 43-49.

Junaidi, Y. R. Sembiring, dan T. H. S. Siregar. 2015. Pengaruh perbedaan letak geografi terhadap pola produksi tahunan tanaman karet: Faktor penyebab perbedaan pola produksi tahunan tanaman karet. Warta Perkaretan, 34(2), 137-146.

Junaidi. 2013. Hasil Uji coba Aplikasi Stimulan Gas LET I System untuk Meningkatkan Produktivitas Tanaman Karet di Kebun Jalupang PTP Nusantara VIII. Penelitian Sungei Putih, Pusat Penelitian Karet 2013.

Karyudi, Sumarmadji, dan E. Bukit. 2006. Penggunaan Stimulan Gas Etilen Untuk Meningkatkan Produktivitas Tanaman Karet. Prosiding Lokakarya Nasional Budidaya Tanaman Karet 2006. Medan, 4 6 September 2006.201 hal.

Kramer. 1983. Water relations of plants. Florida:Academic Press Inc.

Oktavia, F., dan M. Lasminingsih. 2010. Pengaruh kondisi daun tanaman karet terhadap keragaman hasil sadap beberapa klon seri IRR. Jurnal Penelitian Karet. 29(2), 32-40.

Priyadarshan, P.M., S. Sasikumar, and D. Concalves. 2001. Phenological changes in Hevea brasiliensis under differential geo climates. The Planter, 77, 447-481.

Purwaningrum, Y. 2016. Kajian Fisiologi Dan Produksi Tanaman Karet Dengan Berbagai Sistem Sadap Menggunakan Stimulan Gas. [disertasi]. Universitas Sumatera Utara.

Sayurandi, D. Wirnas, dan S. Woelan. 2017. Pengaruh dinamika gugur daun terhadap keragaman hasil lateks beberapa genotipe karet harapan hasil persilangan 1992 di pengujian plot promosi. Warta Perkaretan 2017, 36(1), 1 - 14.

Siregar, T.H.S. 2001. Tanggap Produksi dan Karakter Fisiologi Lateks terhadap Sistem Eksploitasi pada beberapa Klon Karet IRR seri 100. Tesis. Program Pasca Sarjana. Institut Pertanian Bogor. 60 hal.Siregar, T.H.S., Tohari, Hartiko, H., dan Karyudi. 2007. Dinamika perontokan dan pohon 
karet dan hasil lateks: I. Jumlah daun rontok dan hasil lateks. Jurrnal Penelitian Karet, 25(1), 45-58.

Siregar, T.H.S. 2014. Pola musiman produksi dan gugur daun pada klon PB 260 dan RRIC 100. J. Penelitian Karet. 32(2): 88-97.

Siregar, T.H.S., Junaidi, dan Sumarmadji. 2007. Perkembangan Implementasi Sistem Eksploitasi Tanaman karet Tipologi Klonal di Perusahaan Besar Negara Balai Penelitian Sungei Putih, Pusat Penelitian Karet.

Sumarmadji. 2005. Pengaruh Penyadapan Intensitas Rendah Terhadap Produksi dan Serangan KAS. J. Penelitian Karet, 23 (1),58-67.

Sumarmadji. 2011. Sistem Eksploitasi Tanaman berdasarkan Tipologi Klon (QS dan SS) dan Alternatif Sistem Eksploitasi lainnya (Expex-315 dan SS-CUT). Workshop Penggunaan Klon Unggul Baru dan Sistem Eksploitasi Tanaman Karet yang Tepat dalam Menghadapi Peningkatan Karet Alam Dunia. Medan 6 - 9 Desember 2011.

Sumarmadji dan Atmaningsih. 2013. Prinsip Dasar Penyadapan Tanaman Karet. Workshop Eksploitasi Tanaman Karet Menuju Produktivitas Tinggi dan Umur Ekonomis Optimal. Medan, 18 - 21 Maret 2013
Sumarmadji, Atminingsih, dan Karyudi. 2008. Konsep Penyadapan Klon Slow Stater dengan Stimulan Gas Etilen dan Irisan Pendek ke Arah Atas sejak Awal Sadap. Prosiding Lokakarya Agribisnis Karet 2008, Yogyakarta 20 - 21 Agustus 2008. Balai Penelitian Sungei Putih, Pusat Penelitian Karet, Medan. hlm. 375 - 386.

Sumarmadji, Karyudi, dan T. H. S. Siregar. 2006. Rekomendasi Sistem Eksploitasi pada Klon Quick Starter dan Slow Starter serta Penggunaan Irisan Ganda untuk Meningkatkan Produktivitas Tanaman Karet. Prosiding Lokakarya Nasional Budi Daya Tanaman Karet, Medan 4-6 September 2006. Balai Penelitian Sungei Putih, Pusat Penelitian Karet, Medan. hlm. 169-188.

Syukur, 2019. klon Slow Starter (SS). http:/ / syukur.blogdetik.com/2012/09/20/ $>$ klon slow starter (diakses 20 Januari 2020).

Wijaya, T. dan I. Boerhendhy. 1988. Hubungan neraca air tanah dengan produksi karet klon GT 1 dan PR 261. Bulletin Perkebunan Rakyat. 4(1), 15-18. Workshop Eksploitasi Tanaman Karet Menuju Produktivitas Tinggi dan Umur Ekonomis Optimal. Medan, 18 - 21 Maret 2018. 